\title{
Open Modular Hardware and Software Kit for Creations of Remote Experiments Accessible from PC and Mobile Devices
}

\author{
http://dx.doi.org/10.3991/ijoe.v12i07.5833 \\ F. Lustig ${ }^{1,2}$, J. Dvorak ${ }^{1}$, P. Kuriscak ${ }^{1}$, P. Brom ${ }^{1}$ \\ ${ }^{1}$ Charles University, Prague, Czech Republic \\ ${ }^{2}$ RNDr. Frantisek Lustig — Small and Medium Enterprise ISES, Prague, Czech Republic
}

\begin{abstract}
The goal of this paper is to introduce open modular hardware and software system "iSES Remote Lab SDK" (iSES - internet School Experimental Studio) designed for easy creation of real remotely controlled laboratories (RCL) that are accessible from PC, tablets and mobile phones. Open modular system "iSES Remote Lab SDK" consists of approx. 20 freely distributable JavaScript objects in a commented source code. Widgets are highly configurable and provide many well documented options and allow to build a complex measurement and control interface with data and video transfer. Open modular system "iSES Remote Lab SDK" can communicate with different measurement platforms (ISES, Arduino are ready; CMA CoachLab, Vernier etc. are tested), and also common universal measurement devices with a COM or USB port, further universal rotation and linear motion stepper motors, etc.). We will introdukce our 18 online advanced remote labs. Any user may have an access to the RCL on PC and mobile devices (iPad, smart phone, etc.) as well. Even non-programmers can build up a simple RCL and publish it in 15 minutes on the Internet! System "iSES Remote Lab SDK" has obtained the GOLC Online Laboratory Award 2016 in the category Remote Controlled Lab [1].
\end{abstract}

Index Terms-Remote laboratory; software and hardware SDK; JavaScript; HTML5; mobile technology.

\section{INTRODUCTION}

Firstly, we discuss very briefly why only a few open remote labs are available on the Internet nowadays. In this paper we describe a simple software and hardware kit "iSES Remote Lab SDK" that might help to increase the number of real remote experiments.

Remote experiments naturally started appearing with the advent of internet around 1991. First papers on this topic can be found e.g. in [2], [3], [4] and many others.

These experiments required specialized software on boths sides of their client-server architecture. Together with proliferation of web pages and applications, some of the remote experiments started utilizing web browsers as their client-side software.

First remote experiments of authors were created around 2001-2002 and they were based on Java runtime browser plugin [5]. This was feasible for a long time, until security issues started reducing their usability and ultimately rendered JRE obsolete as web technology around 2013.
JavaScript took the dominant role of website interactivity and the experimental interfaces had to be completely reworked.

We can see the development of remote laboratories in review works. In 2004 there were approximately 60 remote laboratories, in 2006 the number rose to 120 and in 2011 there were already over 300 remote laboratories created - see [6], [7]. It is important to note that only 17 of 300 laboratories in 2011 fulfilled non-stop and public availability, with e-text support, and without password access. Another review study of 100 remote experiments can be found in [8].

The newest overview study of remote experiments appeared in 2016 where 61 remote laboratories were mentioned [9]. Our project [10] already using "iSES Remote Lab SDK" is also mentioned there. Another notable project is RemLabNet [11] that also uses the same library. More projects in the overview are WebLab Deusto from Universidad de Deusto in Spain [12], Galileo Group Remote Laboratory [13], Physil@b [14], Mobile Remote Laboratory [15], Remote Experimentation Laboratory RExLAB [16], UNEDLabs [17] and many others.

Another big project GO-LAB [18] provides only 44 remote experiments (25-Feb-2016). More reviews of remote labs can be found in books [19], [20].

Why are there so few remote experiments? Perhaps they are too expensive, require constant service and it is hard to create new ones.

Why are there so few remote experiments? After 2010 many of the existing remote experiments started to dissapear. Universities started to actively block access with passwords and made their remote experiments accessible to their own students only.

Why are there so few remote experiments? We feel that too many institutions concentrate on RLMS, clouds [21][24], Massive Open Online Courses (MOOCs) and Massive Open Online Labs (MOOLs) [25] etc., but no more new remote experiments are created actually.

Most of the remote experiments are based on LabVIEW hardware, e.g. [26]-[29], or DIY (Do-It-Yourself) development platforms with microcontrollers. Recently we can see remote experiments based on FPGA development platform [30], [31].

It should be noted that LabVIEW platform does not yet offer a user-friendly solution for experiment control using web browser - runtime engine has to be installed. Access from smart phones is also problematic - see [32]. The 
LabVIEW Run-time Engine is necessary to view Remote Front Panels. You must use the plugin that corresponds with the version of the LabVIEW Run-Time Engine that you are using. Accessing Remote Front Panels requires the use of NPAPI plugins, which are not supported in any version of Google Chrome (Version 42 or higher), or in Microsoft Edge.

That's why we developed hardware and software kit "iSES Remote Lab SDK" that can be used for easy creation of both simple and complicated remote laboratories utilizing wide spectrum of measuring hardware - professional expensive equipment but also low-cost platforms like Arduino. Specifically Arduino DIY (Do-It-Yourself) platform can effectively motivate many teachers and students in their effort to create their own remote experiments.

\section{Simple Modular Hardware AND Software Kit "ISES REMOTE LAB SDK"}

"iSES Remote Lab SDK" is an open modular hardware and software kit designed for easy creation of real remotely controlled laboratories (RCLs) that are accessible from PC, tablets and smart phones. This open development kit enables even beginners to build up their professional RCLs, ideal for education purposes. Developers may use any available common hardware. In order to share your experimental setup with the other Internet users, you only need to put our widget components together, which is also very easy. Remotely controlled labs based on iSES Remote Lab SDK provide the remote control and measurement with live video stream, easy experimental data record and download for further processing e.g. in MS Excel.

\section{A. Hardware kit of "iSES Remote Lab SDK"}

Open modular system "iSES Remote Lab SDK" can communicate with different measurement platforms (ISES [33]-[36] and Arduino [37] are ready; CMA CoachLab [38], Vernier [39] etc. are tested), and also with common universal measurement devices connected via a COM or USB port, e.g. multimeters like UT-61E, environmental multimeter DT-2232, power supply PSP 1405, ISES USB Geiger-Müller Counter, Ocean Optics USB 2000 series spectrometer, further universal rotation and linear motion stepper motors, or also school kits like the Phywe FranckHertz experiment.

\section{Hardware and software kit for remote labs with systems ISES}

The system ISES has been developed at the Faculty of Mathematics and Physics, Charles University since 1985 (starting with 8-bit PCs with DOS up to contemporary ISES system for PCIe, USB, LAN under 64/32-bit Windows 10, [33]-[36]).

ISES has 20 modules and sensors for Physics, Chemistry, Biology for remote or local experiments: input modules/sensors (temperature, voltmeter, ammeter, ...), output modules/sensors (relay, repro, booster, etc.). For more details and technical parameters about ISES modules see [40]. Furthermore, it is possible to use Vernier, Pasco, etc. analog sensors or your own device for that we can produce extra special plugins.

The system ISES Professional features 4x analog input channels for modules/sensors $(0-5 \mathrm{~V}), 2 \mathrm{x}$ analog input

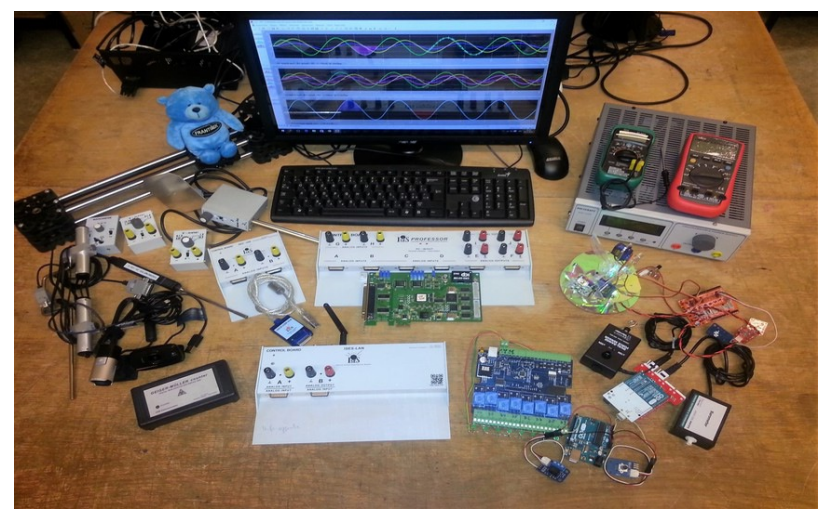

Figure 1. Hardware kit of "iSES Remote Lab SDK" with a different measurement platforms
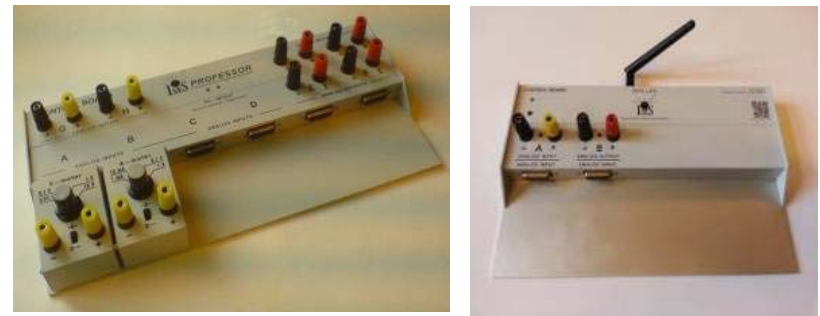

Figure 2. System ISES-Professional, ISES-LAN

channels for (yellow) sockets $(0-5 \mathrm{~V}), 2 \mathrm{x}$ analog output channel $(-5 \mathrm{~V}-+5 \mathrm{~V})$ for modules/sensors, $2 \mathrm{x}$ digital output channels for red sockets, sampling frequency $100 \mathrm{kHz}$, PCI or PCIe (PCI express) ADDA 12-bit card. Software "iSES Remote Lab SDK" can handle up to 4 ISES-PCI Professional units.

The newest system ISES-LAN belongs to IoT (Internet of Things), and includes a PC with Windows 10 operating system, 2GB RAM, 32/64 GB SSD disk, LAN, WiFi, BT 4.0, HDMI, 3x USB ( 1 of them is required for ISES-LAN I/Os if used), repro (not Arduino, Raspberry Pi, ...). ISESLAN features $2 \mathrm{x}$ analog input channels for modules/sensors $(0-5 \mathrm{~V}), 1 \mathrm{x}$ analog output channel for modules/sensors or control voltage $(-5 \mathrm{~V}-+5 \mathrm{~V}$, red socket), $5 \mathrm{x}$ digital outputs/inputs, sampling frequency $100 \mathrm{kHz}$. Software "iSES Remote Lab SDK" can handle up to 4 ISES-LAN units.

\section{Hardware and software kit for remote labs with Arduino}

You may use the Arduino platform to create a remote laboratory experiment at very low costs. Arduino is used as $A D D A$ device only, not as a programmable control element. Here we exploit only analog input pins A0-A5, and digital I/O pins D0-D13 for Arduino Uno, since for other Arduino boards (e.g. Arduino Mega, Galileo etc.) all the analog and digital I/O may be exploited. Minimal requirements for Arduino remote labs are: any Arduino board, software "iSES remote Lab SDK" with the plugin Arduino, and a PC with WinXP-Win10 OS, with LAN and Internet.

\section{Arduino and "iSES Remote Lab SDK - lite version"}

For simple remote experiment we need only any Arduino board and the freeware "iSES Remote Lab SDK lite version", (downloadable at the front page [10]). Lite version has only one analog input pin A0 (e.g. for temperature sensor) and one digital output pin D3 (e.g. for relay). Therefore the freeware "iSES Remote Lab SDK - lite 
version" allows measurement with 1 analog input, control for 1 digital output, data record and export (e.g. to MS EXCEL).

Arduino and "iSES Remote Lab SDK - full version"

Software "iSES Remote Lab SDK - full version" enables to create remote experiments with all platforms of Arduino (Uno, Due, Mega, Galileo, Leonardo, etc.). Full version has 15 analog input pins A0-A15 (e.g. for temperature sensor, light sensor, etc.) and 15 digital $\mathrm{I} / \mathrm{O}$ pins D0-D15 (e.g. for relay or PWM for servo, etc.). Software "iSES Remote Lab SDK - full version" allows measurement with 15 analog inputs, control for 15 digital outputs, data record and export (e.g. to MS EXCEL), and more 15 widgets for advanced management and processing. $S D K^{\prime \prime}$

Arduino and Vernier Sensors with "iSES Remote Lab

Arduino Shield for Vernier sensors and software "iSES Remote Lab SDK" enables to create remote experiments with all the Arduino platforms (Uno, Due, Mega, Galileo, Leonardo, etc.) and with analog or digital Vernier sensors.

Arduino Relay board and "iSES Remote Lab SDK"

Special board with Arduino Duemilanove and 8 relays $(240 \mathrm{~V} / 1 \mathrm{~A} \mathrm{DC})$ is useful for relay-control of a remote experiment.

Hardware and software kit for remote labs with common laboratory instruments

\section{Multifunction Environment Meter CEM DT-2232}

The 4in 1 environment meter CEM DT-2232 can be connected via RS-232 interface, providing measurement at frequency $1.5 \mathrm{x} / \mathrm{sec}$. It is an ideal device for both professional and home applications with measurement of lighting (40-40000 Lux), sound (130 dB), humidity (95\% RH), and temperature $\left(-20^{\circ} \mathrm{C}-+750^{\circ} \mathrm{C}\right)$.

\section{Laboratory power supply PSP 1405}

The laboratory power supply PSP 1405 can be fully operated and controlled by RS-232, providing output voltage 0-40 VDC, and output current 0-5 A.

\section{USB Geiger-Müller counter}

USB Geiger-Müller counter is available with USB or ISES interface, requiring no external power supply.

Stepper motors, linear positioning, XY positioning

Robust industrial linear or XY positioning device is suitable for non-stop operating remote experiments, featuring advanced settings of the velocity and acceleration.

\section{iSES Remote Lab SDK}

with Arduino

Only one universal iSES Remote Lab SDK software
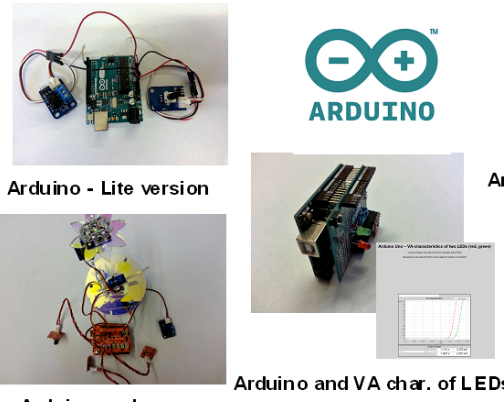

Arduino and VA char. of LED

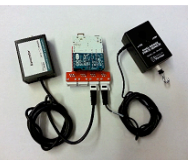

Arduino and Vernier sensors

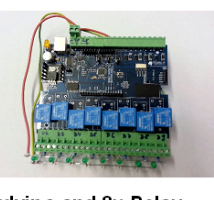

Figure 3.

Arduino and "iSES Remote Lab SDK"
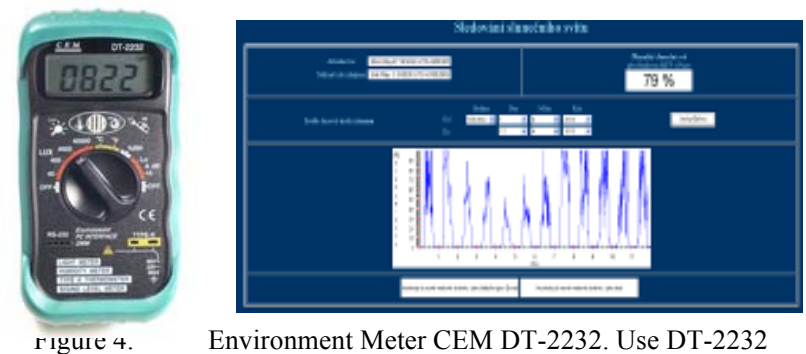

гiguie 4.

Environment Meter CEM DT-2232. Use DT-2232 for remote experiment Sunshine intensity monitoring

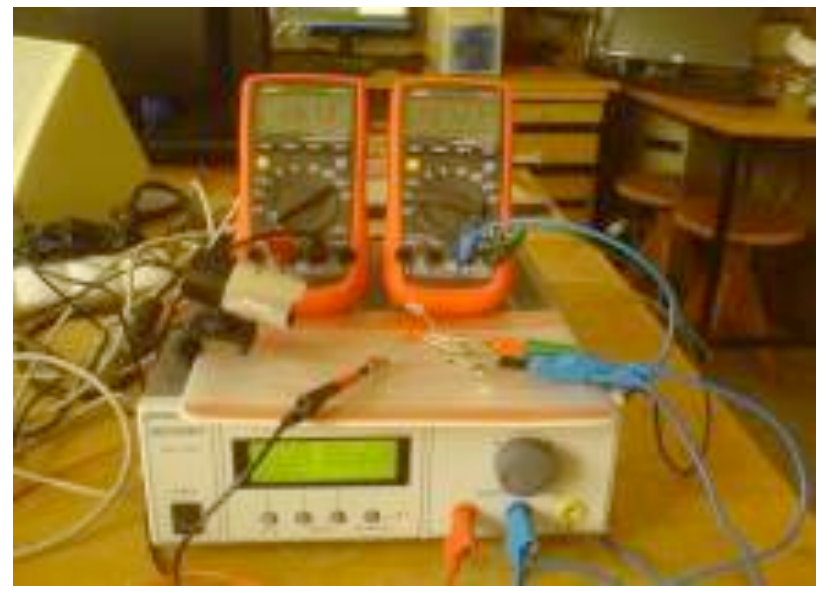

Figure 5. Power supply PSP 1405, RS232 and Multimeter UT61E, RS232, V-A characteristics of LEDs.

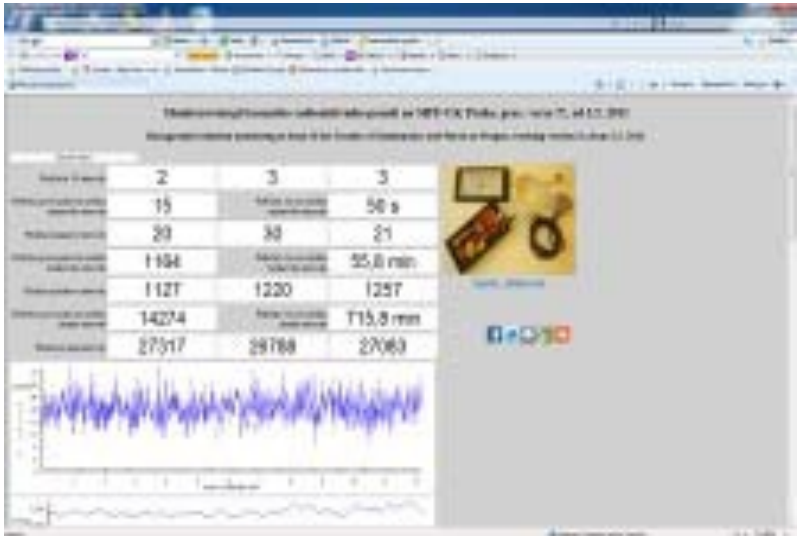

Figure 6. Remote experiment Background radiation monitoring with USB G-M Counter, http://kdt-26.karlov.mff.cuni.cz/.
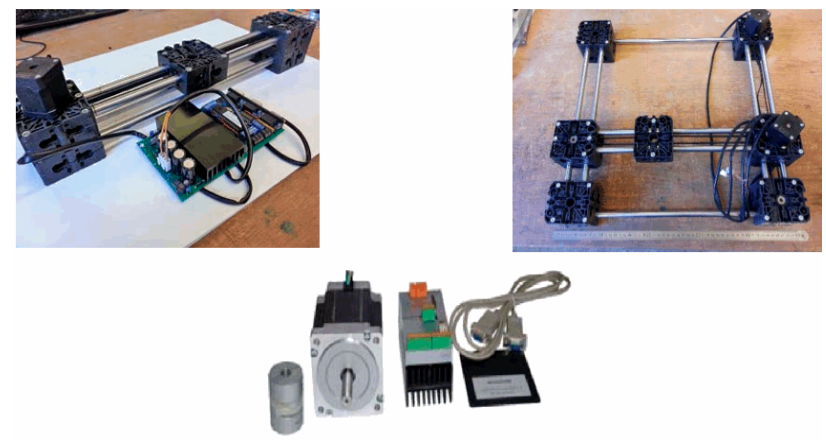

Figure 7. Linear positioning, XY positioning with control board Stepper motor, RS-232 


\section{Water level control}

Remote Water Level Control is a remote laboratory demonstration. It represents multi-user and very simple remote control for beginners.

Phywe Franck-Hertz experiment kit as a remote lab

Traditional school aids like the Phywe Franck-Hertz experiment can be simply transformed to a remote laboratory where a webcam view offers more details visible in a neon tube than what one can see with a naked eye.

\section{Possible combinations of hardware platforms for your remote lab}

The hardware and software kit "iSES Remote Lab SDK" enables to build a remote experiment not only with one hardware platform (ISES or Arduino or with common laboratory instruments (multimeters, power supplies, etc.), but the remote experiment can be assembled from any combination of heterogeneous data acquisition systems or devices. Therefore anyone can create quite complicated remote experiment without limitations.

In order to build a remote experiment using more heterogeneous data acquisition devices, it would be useful to work e.g. with measurement systems like Vernier, Pasco, CMA Coach, etc. that have no output channel (analog or digital). These systems cannot provide control-type remote experiments that allow to change parameters of the experiment. Thus combinations like Vernier plus Arduino might satisfy anyone's requirements on both remote measurement of quantities (sensing) and the control of the remote experimental setup as well.

\section{More remote experiments on one computer}

The kit "iSES Remote Lab SDK" features the possibility to run more remote experiments simultaneously on one computer, which might offer a solution for only one public IP address. The number of remote experiments controlled by one computer depends on the PC performance, the speed of Internet connection, and it is determined by video stream transfer.
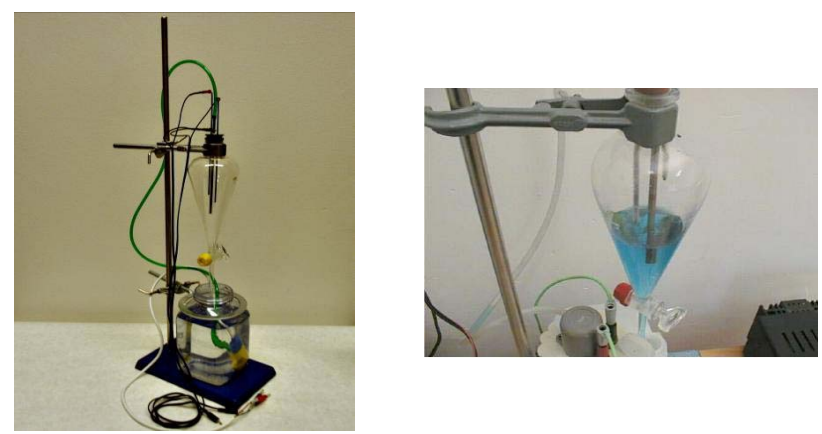

Figure 8. Water Level Control
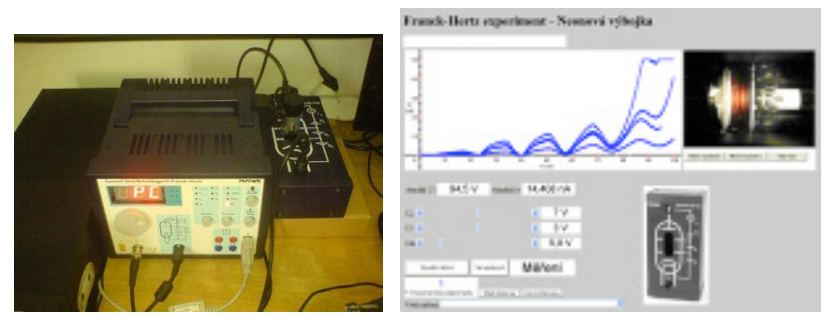

Figure 9.

Phywe Franck-Hertz experiment as remote experiment Apparatus is situated at the Pedagogical faculty of Masaryk University in Brno, available on website http://147.251.192.82

\section{B. Software kit of "iSES Remote Lab SDK"}

\section{Client-server design}

Server-side part of a remote experiment consists of experimental hardware connected to a dedicated computer, which runs MeasureServer and optionally ImageServer application. MeasureServer provides two-way communication with the hardware, while ImageServer creates a video stream captured by the webcam. As the real-time data connection is realized by WebSocket technology, a web server must also be installed and running. In most of our experimental setups the web server runs on the same dedicated computer and serves both user interface in a form of webpage and relays the WebSocket connection to the MeasureServer.

Clients connect to the experiment through regular web browsers. Client browser has to support JavaScript and WebSocket technologies. These are however standard features of all modern browsers in most devices and are required by various other internet applications. In case the WebSocket protocol is not supported on client side, connection automatically switches to HTTP fallback so that measurement is still possible, although with degraded performance.

\section{iSES Remote Lab SDK for user interface design}

To build the actual user interface of the experiment we have prepared a library of approx. 20 JavaScript components (widgets). This library is freely distributable under Creative Commons license and their source code is commented and freely modifiable by experienced programmers.

However, widgets are highly configurable and provide many thoroughly documented options, which are available by default and which allow even non-programmers to build a complex measuring and controlling interface with data and video transfer. Among built-in features, users have access to real-time spline interpolation, simple processing, export of data in various formats, graphical output and other sophisticated functionality.

User interface widgets are mostly based on JQuery and few other freely available JavaScript libraries that are distributed together with the SDK. By using these standard elements, the user interface visual design is also highly customisable. Web-page developers are able to alter the default design using standard methods (mostly CSS) to fit the webpage in which the interface is embedded.

Widgets cover all standard interface elements that are needed for design and control of the experiment. There are three basic groups:

1. VLButton, VLOptionSwitcher, VLSlotValueSelect, VLDatePicker and VLSlider are direct UI elements that are used for hardware control.

2. VLDataOutput, VLValueDisplay, VLChart and VLCamera are designed for display of experimental data. Either in the form of file export or visual chart. Before their display the data can be arbitrarily preprocessed. Great effort was put into the design of the preprocessing chains, so that all types of output share the same data settings. Therefore, the data acquisition method (e.g. realtime vs. recorded), data processing and data output method are configurable independently and can be freely changed during the development without affecting others. 
From the log-record (see Table 2) we can read that a student selected the measurement of the Volt-Ampere characteristics of a vacuum phototube (mode 0 at the beginning) and had to wait in a queue for 88 seconds till he took control of the experimental setup. He switched the mercury lamp on (Sv1) and after approx. 5 min of playing and getting familiar with the interface he started data recording and systematically measured all the V-A characteristics for six available frequencies of light (Sf0-5). The student always used automatic measurement (Ma1) that takes approx. $40 \mathrm{~s}$. Finally he stopped recording (Ps) and downloaded $(\mathrm{Pd})$ his own data for further processing determination of the stopping-voltage values and the experimental value of Planck constant. The value in curly brackets $\{\ldots\}$ corresponds to the time duration since previous action in seconds. Parentheses (...) contain a parameter, e.g. an index of the selected filter.

Furthermore, log records include some basic classification of activities for statistical analysis ( $\mathrm{S}-$ settings, $\mathrm{M}-$ measurement, $\mathrm{P}$ - advanced processing of data). We managed to find 4-5 behaviour patterns, e.g. students' decisions to download and process someone else's data records when he/she is completely lost or because of traffic jams just before deadline. We also detected some kind of students' disengagement and perhaps confusion by the user interface, which helps to develop new and better remote laboratories and to improve user interface as well. Details can be found in [44], [45].

\section{CONCLUSIONS}

We have introduced the hardware and software kit "iSES Remote Lab SDK" suitable for easy creation of real remotely controlled experiments. The hardware kit can be combined of different measurement platforms (e.g. Arduino), common universal measuring devices, and professional control and measurement systems like ISES. The software kit "iSES Remote Lab SDK" consists of approx. 20 freely distributable JavaScript widgets under the Creative Commons licence (CC BY-NC-SA).

The freeware "iSES Remote Lab SDK - lite version" and Arduino platforms can be exploited by beginners for a simple and good-quality remote experiment. We believe in increase of the number of real remotely controlled experiments.

We declare that anyone can freely use the direct links to our remote experiments accessible 365/7/24 at http://www.ises.info/index.php/en/laboratory, providing that we are informed about its usage so that we can have some feedback and data for the development, improvement, and scientific research purposes. Thank you for your collaboration and sharing your experience with iSES remote labs with us.

\section{REFERENCES}

[1] GOLC Online Laboratory Award 2016 in the category Remote Controlled Lab, [Online]. Available: http://ises.info/images/ GOLC_Award.jpg, [Accessed: 04-May- 2016].

[2] B. Aktan, C. Bohus, L. Crowl, and M. H. Shor, „Distance Learning Applied to Control Engineering Laboratories", IEEE Transactions on Education, Vol. 39, No. 3, August 1996, pp. 320-326. http://dx.doi.org/10.1109/13.538754

[3] D. Schumacher, "Student Undergraduate Laboratory and Project Work," editorial to the special issue, Eur. J. Phys., Vol. 28, No. 5, 2007.
[4] F. Schauer, F. Lustig, J. Dvorak, M. Ozvoldova, "An easy-tobuild remote laboratory with Data Transfer Using the Internet School Experimental System", Eur. J. Phys, Vol. 29, 2008, pp. 753-765. http://dx.doi.org/10.1088/0143-0807/29/4/010

[5] ISES WEB Control - software pro vzdalene laboratore se soupravou ISES, 2002-2012, in Czech only, unpublished. [Online] http://www.ises.info/old-site/index.php?f=relizace_vzde xp , Available: http://www.ises.info/index.php/en , [Accessed: 04May- 2016].

[6] S. Gröber, M. Vetter, B. Eckert, and H.-J. Jodl, "Experimenting from a Distance-Remotely Controlled Laboratory (RCL)". Eur. J. Phys, Vol. 28, pp. 127-141, 2007 http://dx.doi.org/10.1088/01430807/28/3/S12

[7] S. Gröber, M. Vetter, B. Eckert, H.-J. Jodl, „Experimentieren aus der Ferne RCL-Experimente für den Physikunterricht der Oberstufe“, 2014 [Online] Available: http://www.discoverlab.com/ References/Experimenting\%20from $\% 20 \mathrm{a} \% 20$ Distance.pdf , [Accesed: 4-May-2016].

[8] L. Gomes and S. Bogosyan, "Current Trends in Remote Laboratories," in IEEE Transactions on Industrial Electronics, vol. 56, no. 12, pp. 4744-4756, Dec. 2009. http://dx.doi.org/10.1109/TIE.2009. 2033293

[9] C. A. Matarrita, S. B. Concari, „Remote laboratories used in physics teaching: a state of the art", in Proceedings of the REV 2016, 13th International Conference on Remote Engineering and Virtual Instrumentation, Madrid, Spain, 2016, pp. 376-381.

[10] e-laboratory project iSES, [Online]. Available: http://www.ises.info/index.php/en, [Accessed: 04- May- 2016].

[11] REMLABNET, [Online]. Available: http://www.remlabnet.eu, [Accessed: 04- May- 2016].

[12] WebLab Deusto, [Online]. Available: https://weblab.deusto.es/ $\mathrm{weblab} /$ client $/$ ?locale $=$ es\#page $=$ experiment\&exp.category $=$ Visir experiments\&exp.name=visir, [Accessed: 04- May- 2016].

[13] Galileo Group Remote Laboratory, [Online]. Available: http://galileo4.unl.edu.ar/descripcionVolante.html, [Accessed: 04May- 2016].

[14] [(Physil@b [Online]. Available: [(http://physilab.ucp.edu.co/ web/\#), [Accessed: 04- May- 2016].

[15] Mobile Remote Laboratory, [Online]. Available: http://labremf4a.fceia.unr.edu.ar/labs/solargsm/, [Accessed: 04May- 2016].

[16] Remote Experimentation Laboratory RExLAB, [Online]. Available: http://relle.ufsc.br/, [Accessed: 04- May- 2016].

[17] UNEDLabs, Available: http://unilabs.dia.uned.es/, [Accessed: 04May- 2016].

[18] GO-LAB, [Online]. Available: http://www.golabz.eu/, ,Accessed: 04- May- 2016].

[19] L. Gomes and J. Garcia-Zubia, Eds., Advances on Remote Laboratories and E-Learning Experiences, Bilbao, Spain: Univ. Deusto, Jun. 2007.

[20] J. Garcia-Zubia, and G. Alves, Using Remote Labs in Education, Ed. University of Deusto, Bilbao, Spain, 2011, ISBN: 978-849830-335-3 [Online], Available: http://www.weblab.deusto.es/ web/weblab.content/using remote labs in education.pdf., [Accesed: 4-May-2016].

[21] F. Schauer, M. Krbecek, P.Beno, M. Gerza, L. Palka and P. Spilaková: "REMLABNET - open remote laboratory management system for e-experiments," in Proceedings of the REV 2014, Porto, Portugal, ISBN 978-1-4799-2025-9. http://dx.doi.org/10.1109/ rev.2014.6784273

[22] F. Schauer, M. Krbecek, P.Beno, M. Gerza, L. Palka and P. Spilaková: "REMLABNET II - open remote laboratory management system for university and secondary schools research based teaching,"'in Proceedings of the REV 2015 - New York : IEEE, Bangkok, Thailand, 2015, ISBN 978-1-4799-7839-7.

[23] F. Schauer et al.: "REMLABNET III - federated remote laboratory management system for university and secondary schools", in Proceedings of the REV 2016, Madrid, Spain, 2016, pp. 232-235.

[24] P. Orduna at al: „Classifying online laboratories: reality, simulation, user perception and potential overlaps", in Proceedings of the REV 2016, 13th International Conference on Remote Engineering and Virtual Instrumentation, Madrid, Spain, 2016, pp. 218-224, ISBN:978-1-4673-8245-8. 
[25] Ch. Salzmann1, Y. Piguet, D. Gillet, "MOOLs for MOOCs, a first edX scalable implementation", in Proceedings of the REV 2016, 13th International Conference on Remote Engineering and Virtual Instrumentation, Madrid, Spain, 2016, pp. 240-245, ISBN:978-14673-8245-8.

[26] KO, Chi Chung, et al. Development of a web-based laboratory for control experiments on a coupled tank apparatus. Education, IEEE Transactions on, 2001, 44.1: 76-86.

[27] P. Bauer et al. Survey of distance laboratories in power electronics. In: Power Electronics Specialists Conference, 2008. PESC 2008. IEEE. IEEE, 2008. p. 430-436.

[28] D. Hercog et al. A DSP-based remote control laboratory. Industrial Electronics, IEEE Transactions on, 2007, 54.6: 3057-3068.

[29] R. Szabo; I. Lie. Automated colored object sorting application for robotic arms. In: Electronics and Telecommunications (ISETC), 2012 10th International Symposium on. IEEE, 2012. p. 95-98. http://dx.doi.org/10.1109/isetc.2012.6408119

[30] Y. Toyoda, N. Koike and Y. Li, "An FPGA-based remote laboratory: Implementing semi-automatic experiments in the hybrid cloud," 2016, in: 13th International Conference on Remote Engineering and Virtual Instrumentation (REV), Madrid, 2016, pp. 24 29, http://dx.doi.org/10.1109/REV.2016.7444435

[31] L. Rodriguez-Gil1, P. Orduña, J. García-Zubia: “Graphic Technologies for Virtual, Remote and Hybrid laboratories: WebLabFPGA hybrid lab, in: Proceedings 11th International Conference on Remote Engineering and Virtual Instrumentation (REV), Porto, Portugal, 2014, pp.164-166, ISBN:978-1-4799-2025-9

[32] LabVIEW Run-time Engine and Remote Front Panels [Online]. Available: http://digital.ni.com/public.nsf/allkb/151BE12C055F57 CE86257043006CB4B3, [Accessed: 04- May- 2016].

[33] F. Lustig, F. Schauer, „Creative laboratory experiments for basic physics using computer data collection and evaluation exemplified on the ISES", in Proceedings of The first European conference on Physics Teaching in Engineering Education, ed. Oehlenschlaeger, Copenhagen, Denmark, 1997, pp. 125-131.

[34] F. Schauer, I. Kuritka and F. Lustig, "Creative Laboratory Experiments for Basic Physics Using Computer Data Collection and Evaluation Exemplified on the Intelligent School Experimental System (ISES)", Innovations 2006, World Innovations in Engineering Education and Research, iNEER Special Volume, W. Aung et al. (eds.), pp. 305-312, USA, 2006.

[35] ISES, 1985- 2016, [Online]. Available: http://www.ises.info/ index.php/en/systemises, [Accessed: 04- May- 2016].

[36] F. Lustig, „Pocitacem podporovane skolni experimenty s mericim systemem ISES pod Windows", in Proceedings MEDACTA 97 vzdelavanie $v$ meniacom sa svete, Ustav didaktickej technologie, PF UKF v Nitre, Nitra, only in Czech, ISBN 80-967339-9-0, 1997, pp. 404-408.

[37] Arduino, [Online]. Available: https://www.arduino.cc/,[Accessed: 04- May- 2016].

[38] CMA CoachLab [Online]. Available: http://www.cma-science.nl/, [Accessed: 04- May- 2016].

[39] Vernier, [Online]. Available: http://www.vernier.com „[Accessed: 04- May- 2016].

[40] ISES modules overview [Online], in Czech only. Available: http://www.ises.info/old-site/index.php?f=moduly, [Accessed: 04May- 2016].
[41] J. Dvorak, P. Kuriscak, F. Lustig, "Remote Lab SDK - internet School Experimental Studio for Remote Laboratory" Software Development Kit, Business and License Agreement: SME RNDr. Frantisek Lustig. U Druhe Baterie 29, 16200 Praha 6, phone +420602858 056, 2013 [Online],. Available: http://www.ises.info/index.php/en/systemises/sdkisesstudio , [Accesed: 4-May-2016], unpublished.

[42] M. Krbecek, F. Schauer and F. Lustig, "EASY REMOTE ISES Environment for Remote Experiments Programming," Innovations 2013: World Innovations in Engineering Education and Research, W. Aung, et al. (eds.), iNEER, Potomac, MD, USA, pp. $80-101$.

[43] M. Ozvoldová and F. Schauer, "Remote Laboratories in Researchbased education of real world phenomena," Peter Lang, Int. Acad. Publ. Frankfurt, F. Schauer (ed.), 157 p., 2015, ISBN 978-3631-66394-3.

[44] Z. Lustigova, P. Brom, "Educational Datamining" in Virtual Learning Environments. iJAC. 2014, 1, 7, 39-42. ISSN: 18675565.

[45] Z. Lustigova, V. Novotna, P. Brom, "Detecting disengagement of online students", in Proceedings DISCO 2014, Praha, Center for Higher Education Studies, 2014, vol. 9, iss. 1, 134-145. ISBN: 978-80-86302-46-1.

[46] J. Ma and J.V. Nickerson, "Hands-On, Simulated, and Remote Laboratories: A Comparative Literature Review". ACM Computing Surveys, vol. 38, no. 3, 2006. http://dx.doi.org/10.1145/ 1132960.1132961

[47] D. Groom, "The Downtime Learner theory", 2011 [Online], Available from: https://deangroom.wordpress.com/2011/04/14/ the-downtime-learner-theory/, [Accessed: 4-May-2016 .

\section{AUTHORS}

F. Lustig is with the Charles University, Faculty of Mathematics and Physics, Prague, Czech Republic. He received his Ph.D. degree in Plasma Physics and he was appointed Associate Professor in Didactics of Physics (e-mail: frantisek.lustig@mff.cuni.cz).

J. Dvorak is with the Charles University, Faculty of Mathematics and Physics, Prague, Czech Republic. He received his masters degree in Computer Science. (e-mail: JiriDvorak@centrum.cz).

P. Kuriscak is with the Charles University, Faculty of Mathematics and Physics, Prague, Czech Republic. He received his masters degree in Mathematical modelling and is currently a PhD. Student of Physics Education. (e-mail: pavel.kuriscak@gmail.com).

P. Brom is with the Charles University, Faculty of Mathematics and Physics, Prague, Czech Republic. He received his masters degree in Optics and Optoelectronics and is currently a PhD. Student of Physics Education. (e-mail: Pavel.Brom@mff.cuni.cz).

Submitted, 07 May 2015. Published as resubmitted by the authors on 09 June 2016 